\title{
EFFICACY OF OXYTETRACYCLINE, AMOXICILLIN, SULFAMETHOXAZOLE AND TRIMETHOPRIM, AND TYLOSIN FOR THE TREATMENT OF BACTERIAL DISEASES IN CATTLE AND GOATS
}

\author{
M. S. Islam ${ }^{1,3}$, M. M. Rahman ${ }^{2}$, M. M. U. Bhuiyan ${ }^{2}$, M. Shamsuddin ${ }^{2,4}$ and M. T. Islam ${ }^{1 *}$ \\ ${ }^{1}$ Department of Medicine, ${ }^{2}$ Community-based Dairy Veterinary Foundation, Department of Surgery and \\ Obstetrics, Bangladesh Agricultural University, Mymensingh-2202, Bangladesh; ${ }^{3}$ Upazila Livestock Office, \\ Tala, Satkhira, ${ }^{4}$ International Atomic Energy Agency, Austria, Vienna
}

\begin{abstract}
A single blind clinical trial was carried out in Satkhira district where dairy operations by Community-based Dairy Veterinary Foundation, Bangladesh Agricultural University, Mymensingh were running. A total of 80 cattle and goats affected with different bacterial diseases were used for treatment with oxytetracycline, amoxicillin, combined preparation of sulfamethoxazole and trimethoprim, and tylosin. Diagnosis of diseases was based on clinical history and signs. Haemorrhagic septicemia (HS) affected cattle aged between 3 and 6 were treated with oxytetracycline (Tetravet-100, Acme, Bangladesh; DUFA-OTC 20\% LA, DutchFarm, Holland). Amoxicillin (Amoxicillin trihydrate, Jickstar Pharma Inc., Philippines; Moxilin Vet LA, The ACME Laboratories Ltd., Bangladesh) was used in the treatment of calf pneumonia. Foot rot in cows, arthritis in calf and goat were treated with sulphamethoxazole and trimethoprim (Politrim-Vet, The ACME Laboratories Ltd., Bangladesh). Bronchopneumonia in non-lactating cows and goats were treated with tylosin (Tylovet (Acme). The efficacy of oxytetracycline, amoxicillin, sulfamethoxazole and trimethoprim, and tylosin for the treatment of haemorrhagic septicemia, calf pneumonia, foot rot and bronchopneumonia were evaluated on the basis of recovery rate. Treatment of haemorrhagic septicemia with both antibiotics showed $100 \%$ recovery rate. The duration of complete recovery in Tetravet-100 treated group was 4-6 days with median of 5 days. In the DUFA-OTC 20\% LA treated group it was 3-5 days with median of 4 days. Moxilin Vet ${ }^{\circledR}\left(\right.$ Acme) and Amoxicillin trihydrate ${ }^{\circledR}$ (Jickstar Pharma) were evaluated against calf pneumonia in cattle. Cent percent cattle were cured with both the antibiotics, Moxilin Vet ${ }^{\circledR}$ (Acme) and Amoxicillin trihydrate ${ }^{\circledR}$ (Jickstar Pharma). For both antibiotics, the median days of complete recovery was 5 . Of 5 foot rot affected cows treated with a combined preparation of sulfamethoxazole and trimethoprim (Politrim-Vet巴, Acme), 4 (80\%) recovered within 4-5 days of treatment. However, treatment of arthritis affected calf and goat with same preparation showed $90 \%$ and $100 \%$ recovery rate, respectively. Treatment of bronchopneumonia cases with tylosin (Tylovet ${ }^{\circledR}$, Acme) resulted in $80 \%$ recovery in non-lactating cows and $90 \%$ in goats and it took 4-5 days for recovery with a median of 4 days.
\end{abstract}

Keywords: Haemorrhagic septicemia, pneumonia, arthritis, foot rot, oxytetracycline, amoxicillin, tylosin

\section{INTRODUCTION}

Haemorrhagic septicemia (HS), a bacterial disease caused by Pasturella multocida, is an important infectious disease of large ruminants in Bangladesh (Debnath et al., 1990; Ahmed, 1996). All ages and types of cattle can be affected but the highest morbidity and mortality occur when beef calves are congregated in feedlots (Yates, 1982). The clinical signs are characterized by coughing, fever, depression, weight loss and death (Hjerpe, 1983). The disease could be effectively treated by the wide range of antibiotics either oxytetracycline or streptomycin (Kedrak and Borkowska-Opacka, 2001). However, penicillin and ampicillin are also widely used (Abeynayake et al., 1993; Kedrak and Borkowska-Opacka, 2001). De Alwis (1995) was found intramuscular administration of streptomycin or oxytetracycline convenient and effective in the treatment of HS. Alongside, antibiotic-resistance is a common feature, and resistance to penicillin is particularly common because widespread use of this antibiotic has created intense selective pressure favoring penicillin resistant organisms (Zimmerman and Hirsh, 1980; Hjerpe, 1983).

*Corresponding e-mail address:taohid@bau.edu.bd 


\section{S. Islam and others}

Pneumonia in pre-weaned calves is a multi-factorial disease involving a well-known group of viruses and bacteria, as well as calf-related and environmental risk factors (Ridpath, 2010). Early signs of calf pneumonia include elevated respiratory rate, fever, serous nasal discharge and at the most mild depression or inappetence (Lorenz et al., 2011). Since early treatment is the most important factor that prevents treatment failure, recognition at this stage would be preferable. Antibiotic treatment of bacterial pneumonia must be sufficient in duration and, most crucially, early enough to prevent lesions forming that may resist both therapy and regeneration of normal lung parenchyma (Woolums et al., 2009). The emphasis should be on early treatment and first treatment success in cases of calf pneumonia since the outcome for those animals that fail to respond successfully to first treatment is poor. Typically, one third to two thirds of animals that do not respond to initial therapy are permanently affected or lost (Sweiger and Nichols, 2010). Amoxicillin, ceftiofur, oxytetracycline, sulfadimethoxine are the common antibiotics used for the treatment of pneumonia and bronchopneumonia globally. Unlike ampicillin, the bioavailability of amoxicillin is comparatively higher in different body tissues (Sawant et al., 2005).

Arthritis is a common cause of lameness in ruminants and frequently occurred cases. Usually, ruminants affected with arthritis are treated with a combined preparation of penicillin and streptomycin, sulfonamides, ceftiofur (Radostits et al., 2006). Foot rot is a highly contagious disease affecting the interdigital (between the toes) tissue of ruminants. It is one of the most common causes of lameness in cattle and can result in serious economic loss. Once present in a herd, foot rot can be very difficult to control (Griffin, 1998). Foot rot is usually treated with an antimicrobial product. Penicillin, tetracycline, and other antibacterial medicines are often used to treat normal cases of foot rot. One antibiotic treatment is usually adequate if administered on the first day of disease. Recovery is generally observed in three to four days. If treatment is not initiated until later in the disease process, multiple treatments may be necessary. Penicillin and oxytetracycline are effective antibiotics if started early in the disease process and given at the recommended dosage. Sulfonamides (either intravenously or as a bolus) work well too (Griffin, 1998).

In Bangladesh, antimicrobials are used for the treatment of bacterial diseases at field level without having confirmatory diagnosis and knowing antibiotic sensitivity results, and the field veterinarians experience a wide range of efficacy of different antibiotics. Most of the research reports on antibiotic efficacy are based on laboratory setting, i.e. in vitro condition. This paper reports the clinical efficacy of some common antimicrobials such as oxytetracycline, amoxicillin, potentiated sulfonamides (Sulphamethoxazole and Trimethoprim) and tylosin to treat a number of bacterial diseases in cattle and goats at field setting based on presumptive diagnosis.

\section{MATERIALS AND METHODS}

A single blind clinical trial was carried out for a period of one year, from September 2011 to August 2012 in Satkhira district where dairy operations by Community-based Dairy Veterinary Foundation, Bangladesh Agricultural University, Mymensingh were running. A total of 80 cattle and goats affected with different bacterial diseases were used for treatment with oxytetracycline, amoxicillin, combined preparation of sulfamethoxazole and trimethoprim and tylosin (Table 1).

Table 1. Clinical cases and number of animals allocated

\begin{tabular}{lc}
\hline Diseases & No. of animals \\
\hline Haemorrhagic septicemia in cattle & 20 \\
Calf pneumonia & 20 \\
Foot rot in cows & 5 \\
Arthritis in calf & 10 \\
Arthritis in goat & 5 \\
Bronchopneumonia & \\
$\quad$ Non-lactating cows & 10 \\
$\quad$ Goats & 10 \\
\hline
\end{tabular}


Efficacy of different antibiotics in cattle and goats

\section{Drugs used}

Amoxicillin trihydrate: Amoxicillin trihydrate (150mg/ml), $100 \mathrm{ml}$ vial, Jickstar Pharma Inc., Philippines, Moxilin Vet LA $(150 \mathrm{mg} / \mathrm{ml})$, The ACME Laboratories Ltd., Bangladesh; Oxytetracycline hydrochloride: Tetravet-100 (100mg/ml), $10 \mathrm{ml}$ vial, The ACME Laboratories Ltd., Bangladesh, DUFA-OTC 20\% LA $(200 \mathrm{mg} / \mathrm{ml}), 100 \mathrm{ml}$ vial, DutchFarm, Holland; Sulphamethoxazole and Trimethoprim: Politrim-Vet (Sulphamethoxazole 200mg and Trimethoprim 40mg/ml), $100 \mathrm{ml}$ vial, The ACME Laboratories Ltd., Bangladesh; Tylosin: Tylovet (200mg/ml), $10 \mathrm{ml}$ vial, The ACME Laboratories Ltd., Dhaka, Bangladesh.

\section{Presumptive diagnosis of diseases}

The haemorrhagic septicemia was diagnosed on the basis of clinical signs, which included high temperature, salivation, swelling of the throat and difficulty in breathing. The clinical cases with increased respiratory rate, respiratory distress with abnormal lung sounds, fever, serous nasal discharge and at the most mild depression or inappetence were diagnosed as calf pneumonia/bronchopneumonia (Lorenz et al., 2011). Foot rot was typically diagnosed by the distinctive lesions and odor. Any interdigital fissures and cracks with a characteristic odor was treated as foot rot. Arthritis was diagnosed by swollen joint which were painful and warm to touch and lameness of varying degrees of severity.

\section{Treatment protocol}

\section{Haemorrhagic septicemia affected cattle}

Twenty affected cattle aged between 3 and 6 years were systematically selected, of which ten were treated with Tetravet-100 (Acme, Bangladesh) @ $1 \mathrm{ml} / 10 \mathrm{~kg}$ body weight IM once daily for 5 days while other ten received two doses of DUFA-OTC 20\% LA (DutchFarm, Holland) @ $1 \mathrm{ml} / 10 \mathrm{~kg}$ body weight IM at 48 hours interval. In addition, all the cattle received ketoprofen (Keto-A Vet, Acme) @ 3 ml/100 kg body weight IM once daily for 3 days.

\section{Calf pneumonia}

Twenty affected calf aged between 4 and 10 months, were systematically selected, of which ten received two doses of Moxilin Vet LA (Acme) @ $1 \mathrm{ml} / 10 \mathrm{~kg}$ body weight IM at 48 hours interval while other ten were treated with Amoxicillin trihydrate (Jickstar Pharma, Inc., Philippines) @ $1 \mathrm{ml} / 15 \mathrm{~kg}$ body weight IM once daily for 5 days. In addition, all the calves received chlorpheniramine maleate (Asta Vet, Acme) @ $1 \mathrm{ml} / 25 \mathrm{~kg}$ body weight IM once daily for 5 days.

\section{Foot rot in cows, arthritis in calf and goat}

A total of 5 foot rot affected cows of 4-5 years old, and 10 arthritis affected calves (10-12 months old) were treated with Politrim-Vet (Acme) @ $1 \mathrm{ml} / 15 \mathrm{~kg}$ body weight IM once daily for 5 days. Five goats affected with arthritis were also treated with Politrim-Vet @ $1 \mathrm{ml} / 10 \mathrm{~kg}$ body weight IM once daily for 5 days. In addition, all the cattle and goats received ketoprofen (Keto-A Vet, Acme) @ 3 ml/100 kg body weight IM once daily for 3 days.

\section{Bronchopneumonia in non-lactating cows and goats}

Ten non-lactating cows and ten goats affected with bronchopneumonia were treated with Tylovet (Acme) @ $1 \mathrm{ml} / 10 \mathrm{~kg}$ body weight once daily for 5 days. In addition, all the cows and goats received chlorpheniramine maleate (Asta Vet, Acme) @ $1 \mathrm{ml} / 25 \mathrm{~kg}$ body weight IM once daily for 5 days.

\section{RESULTS AND DISCUSSION}

The efficacy of oxytetracycline, amoxicillin, sulfamethoxazole and trimethoprim, and tylosin for the treatment of haemorrhagic septicemia, calf pneumonia, foot rot and bronchopneumonia were evaluated on the basis of recovery rate. 


\section{S. Islam and others}

The animals affected with haemorrhagic septicemia were treated with two commercially available antibiotic preparations (Tetravet®, Acme) and (DUFA-OTC 20\% LA, DutchFarm). Treatment of haemorrhagic septicemia with both antibiotics showed $100 \%$ recovery rate (Table 2). The duration of complete recovery in Tetravet-100 treated group was 4-6 days with median of 5 days. In the DUFA-OTC 20\% LA treated group it was 3-5 days with median of 4 days.

Moxilin Vet ${ }^{\circledR}$ (Acme) and Amoxicillin trihydrate ${ }^{\circledR}$ (Jickstar Pharma) were evaluated against calf pneumonia in cattle. Cent percent cattle were cured with both the antibiotics (Table 2). For both antibiotics, the median days of complete recovery was 5 .

Table 2. Duration (days) and recovery rate of animals affected with different bacterial diseases following treatment with oxytetracycline, amoxicillin, sulfamethoxazole and trimethoprim, and tylosin

\begin{tabular}{|c|c|c|c|c|c|}
\hline Name of diseases & Name of drugs & $\begin{array}{l}\text { No. of } \\
\text { animals } \\
\text { treated }\end{array}$ & $\begin{array}{l}\text { No. of } \\
\text { animals } \\
\text { recovered }\end{array}$ & $\begin{array}{l}\text { Duration (days) of } \\
\text { complete recovery } \\
\text { (median days) }\end{array}$ & $\begin{array}{l}\text { Recovery } \\
\text { rate }(\%)\end{array}$ \\
\hline \multirow{2}{*}{$\begin{array}{l}\text { Haemorrhagic septicemia } \\
\text { in cattle }\end{array}$} & Tetravet-100 (Acme) & 10 & 10 & $4-6(5)$ & 100 \\
\hline & $\begin{array}{lll}\begin{array}{l}\text { DUFA-OTC } \\
\text { (DutchFarm) }\end{array} & 20 \% \text { LA } \\
\end{array}$ & 10 & 10 & $3-5(4)$ & 100 \\
\hline \multirow[t]{2}{*}{ Calf pneumonia } & $\begin{array}{lll}\begin{array}{l}\text { Moxilin } \\
\text { (Acme) }\end{array} & \text { Vet } & \text { LA }\end{array}$ & 10 & 10 & $4-7(5)$ & 100 \\
\hline & $\begin{array}{l}\text { Amoxicillin Trihydrate } \\
\text { (Jickstar Pharma Inc) }\end{array}$ & 10 & 10 & 3-7 (5) & 100 \\
\hline Foot rot in cows & Politrim-Vet (Acme) & 5 & 4 & $5-6(5)$ & 80 \\
\hline Arthritis in calf & & 10 & 9 & $5-7(6)$ & 90 \\
\hline Arthritis in goat & & 5 & 5 & 4-7 (5) & 100 \\
\hline Bronchopneumonia & Tylovet (Acme) & & & & \\
\hline Non-lactating cows & & 10 & 8 & $4-5(4)$ & 80 \\
\hline Goats & & 10 & 9 & $4-5(4)$ & 90 \\
\hline
\end{tabular}

Of 5 foot rot affected cows treated with a combined preparation of sulfamethoxazole and trimethoprim (Politrim-Vet®, Acme), 4 (80\%) recovered within 4-5 days of treatment. However, treatment of arthritis affected calf and goat with same preparation showed $90 \%$ and $100 \%$ recovery rate, respectively.

A single preparation of tylosin (Tylovet ${ }^{\circledR}$, Acme) was used for the treatment of bronchopneumonia in nonlactating cows and goats. The result showed that $80 \%$ non-lactating cows and $90 \%$ goats were recovered after treatment and it took 4-5 days for recovery with a median of 4 days (Table 2).

We have evaluated some antimicrobials against some important diseases of cattle and goat under field condition. A limitation of our study is that the confirmatory diagnosis of diseases was not done rather we performed presumptive diagnosis. In Bangladesh, use of antimicrobials in the treatment of animal diseases is mainly based on the presumptive diagnosis of diseases. Therefore, clinical evaluation of antimicrobials under field setting in this study provided some useful information for the field veterinarians.

In the treatment of haemorrhagic septicemia, several antimicrobials are used effectively like oxytetracycline, potentiated sulfonamides (Benkirane and De Alwis, 2002). Here, we found 100\% efficacy with the treatment of oxytetracycline in case of haemorrhagic septicemia, which is in agreement with the earlier report of (Keita et al., 2007; Shivachandra et al., 2011) who also reported higher efficacy of level of oxytetracycline.

Amoxicillin is widely used in veterinary practice (Radostits et al., 2006). In cattle, this antibiotic is indicated in the treatment of many bacterial diseases such as pneumonia, diarrhea, mastitis and even foot rot (Braun et al., 1987; Radostits et al., 2006). It is effective in the treatment of calf pneumonia caused by $P$. hemolytica, $P$. multocida (Benkirane and De Alwis, 2002). Here, Moxilin Vet ${ }^{\circledR}$ (Acme) and Amoxicillin trihydrate ${ }^{\circ}$ (Jickstar Pharma), both the preparations were very effective in the treatment of calf pneumonia. 
In case of arthritis and foot rot treatment, several antimicrobials have been reported to be effective like potentiated sulfonamides, oxytetracycline, and ceftiofur (Kausche and Robb, 2002). Among them the efficacy level of potentiated sulfonamides and ceftiofur is high (Griffin, 1998), which supports the present finding in which $80-100 \%$ efficacy was found with the treatment of potentiated sulfonamides (Politrim-Vet, Acme) in the treatment of foot rot and arthritis.

Tylosin, an antibiotic of the macrolide class, is indicated in the treatment of a wide range of diseases in cattle and goats caused by Gram-positive organisms and a limited range of Gram-negative organisms. Its use in the treatment of bronchopneumonia is also suggested by many authors (Radostits et al., 2006; Prescott and Dowling, 2013). Here, in this study the efficacy of tylosin (Tylovet, Acme) in the treatment of bronchopneumonia in nonlactating cows and goats was 80-90\%, which is consistent with the earlier reports (Stamm and Cobbs, 1980).

\section{REFERENCES}

1. Abeynayake P, Wijewardana TG and Thalagoda SA (1993). Antimicrobial susceptibility of Pasteurella multocida isolates. In: ACIAR PROCEEDINGS, pp 193-193: Australian Centre For International Agricultural Research.

2. Ahmed S (1996). Status of some bacterial diseases of animals in Bangladesh. Asian Livest 21: 112-114.

3. Benkirane A and De Alwis M (2002). Haemorrhagic septicaemia, its significance, prevention and control in Asia. Veterinarni MedicinaPraha 47: 234-240.

4. Braun R, Bates D, Shearer J, Tran T and el Keiey M (1987). Efficacy of amoxicillin trihydrate for the treatment of experimentally induced foot rot in cattle. American Journal of Veterinary Research 48: 1751-1754.

5. De Alwis M (1995). Haemorrhagic septicaemia (Pasteurella multocida serotype B: 2 and E: 2 infection) in cattle and buffaloes. In. Haemophilus, Actinobacillusand Pasteurella, edn: Springer. pp. 9-24.

6. Debnath N, Sil B, Selim S, Prodhan M and Howlader M (1990). A retrospective study of calf mortality and morbidity on smallholder traditional farms in Bangladesh. Preventive Veterinary Medicine 9: 1-7.

7. Griffin DD (1998). Feedlot Diseases. Veterinary Clinic for North America: Food Animal Practice 14: 199-231.

8. Hjerpe C (1983). Clinical management of respiratory disease in feedlot cattle. Veterinary Clinics for North America (USA).

9. Kausche FM and Robb EJ (2002). A comprehensive review of ceftiofur sodium and hydrochloride formulations for treatment of acute bovine foot rot. Veterinary Therapeutics: Research in Applied Veterinary Medicine 4: 83-93.

10. Kedrak A and Borkowska-Opacka B (2001). Phenotypic characteristics of Pasteurella multocida strains isolated from cattle affected with haemorrhagic septicaemia. Bulletin of the Veterinary Institute in Pulawy 45: 171-176.

11. Keita A, Pommier P, Pagot E, Couper A and Cromie L (2007). A combination oxytetracycline/flunixin treatment of respiratory infections in cattle. Revue Médicine Véterinaire 158: 86-91.

12. Lorenz I, Earley B, Gilmore J, Hogan I, Kennedy E and More SJ (2011). Calf health from birth to weaning. III. housing and management of calf pneumonia. Irish Veterinary Journal 64: 1.

13. Prescott JF and Dowling PM (2013). Antimicrobial therapy in veterinary medicine. edn. John Wiley \& Sons.

14. Radostits OM, Gay CC, Hinchcliff KW and Constable PD (2006). Veterinary Medicine. $10^{\text {th }}$ edn. WB Saunders: Philadelphia, USA.

15. Ridpath J (2010). The contribution of infections with bovine viral diarrhea viruses to bovine respiratory disease Veterinary Clinics for North America: Food Animal Practice 26: 335-348.

16. Sawant A, Sordillo L and Jayarao B (2005). A survey on antibiotic usage in dairy herds in Pennsylvania. Journal of Dairy Science 88: 2991-2999.

17. Shivachandra S, Viswas K and Kumar A (2011). A review of hemorrhagic septicemia in cattle and buffalo. Animal Health Research Reviews 12: 67-82.

18. Stamm AM and Cobbs CG (1980). Group C streptococcal pneumonia: report of a fatal case and review of the literature. Review of Infectious Diseases 2: 889-898.

19. Sweiger SH and Nichols MD (2010). Control methods for bovine respiratory disease in stocker cattle. Veterinary Clinics of North America: Food Animal Practice 26: 261-271.

20. Woolums A, Ames T and Baker J (2009). The bronchopneumonias (respiratory disease complex of cattle, sheep, and goats). Large Animal Internal Medicine4: 602-643.

21. Yates W (1982). A review of infectious bovine rhinotracheitis, shipping fever pneumonia and viral-bacterial synergism in respiratory disease of cattle. Canadian Journal of Comparative Medicine 46: 225.

22. Zimmerman M and Hirsh D (1980). Demonstration of an R plasmid in a strain of Pasteurella haemolytica isolated from feedlot cattle. American Journal of Veterinary Research 41: 166-169. 